\title{
MEKANISME IMBAL JASA LINGKUNGAN DI SUB-DAS CIKAPUNDUNG (Studi Kasus pada Desa Cikole dan Desa Suntenjaya Kabupaten Bandung Barat)
}

\author{
Dinda Febrima Napitupulu(1), Chay Asdak ((1,2), Budiono(1,3) \\ (1) Program Studi Magister Ilmu Lingkungan Universitas Padjajaran \\ Email : napitupulu dinda@yahoo.com \\ (2) Program Studi Magister Ilmu Lingkungan Universitas Padjajaran \\ Email : c asdak@yahoo.com \\ (3) Program Studi Magister Ilmu Lingkungan Universitas Padjajaran \\ Email : budionob04@yahoo.com
}

\begin{abstract}
ABSTRAK
Mekanisme Imbal Jasa Lingkungan (IJL) merupakan salah satu upaya dalam pengelolaan sub-DAS. Mekanisme ini telah diimplementasikan di sub-DAS Cikapundung. Kesepakatan program IJL di sub-DAS Cikapundung terjadi antara kelompok tani Giri Putri Desa Cikole dengan Pustanling dan kelompok tani Syurga Air dengan PT Aetra. BPLHD berperan sebagai mediator dalam kesepakatan ini. Pada pelaksanaannya, mekanisme IJL di sub-DAS Cikapundung dikategorikan sebagai mekanisme IJL yang belum sepenuhnya mencerminkan mekanisme IJL yang berkelanjutan. Kriteria mekanisme IJL yang berkelanjutan seharusnya memenuhi aspek-aspek: realistic, voluntarily, conditional, dan pro-poor (Munawir, 2009). Pada mekanisme IJL di sub-DAS Cikapundung hal ini belum sepenuhnya terjadi.

Berdasarkan hal tersebut, penelitian ini bertujuan untuk merumuskan strategi yang dapat dilakukan agar mekanisme IJL di sub-DAS Cikapundung menjadi berkelanjutan. Metode yang digunakan pada penelitian ini adalah metode kualitatif. Pengumpulan data dilakukan melalui wawancara dan kuisioner dengan kelompok tani Syurga Air dan Giri Putri, PT Aetra, Pustanling, BPLHD, serta LP3ES. Analisis yang dilakukan adalah analisis kesenjangan, analisis peran faktor dan analisis SWOT. Mekanisme IJL di sub-DAS Cikapundung belum berjalan secara berkelanjutan dikarenakan masalah dalam kelembagaan dalam pengelolaan dan monitoring perkembangannya di lapangan. Selain itu dana yang diberikan kepada kelompok tani juga masih tergolong belum mencukupi untuk aktivitas konservasi Iahan. Untuk mewujudkan mekanisme IJL yang berkelanjutan maka diperlukan upaya-upaya strategis terutama dalam kaitannya dengan kelembagaan mediasi kesepakatan dengan pembentukan lembaga mediator mekanisme IJL yang bukan dari institusi pemerintah agar fasilitasi, advokasi dan koordinasi mekanisme IJL berjalan lebih optimal, juga perlu dilakukan upaya untuk meningkatkan kepatuhan pada regulasi terkait IJL, meningkatkan optimalisasi setiap forum pertemuan, meningkatkan kinerja stakeholders, serta melakukan negosiasi dengan potential buyer.
\end{abstract}

Kata kunci: imbal jasa lingkungan, sub-DAS Cikapundung, strategi SW OT

\section{ABSTRACT}

Payment for Environmental Service (PES) is one of the ways in managing the subwater shed. This mechanism has been implemented in Cikapundung sub-watershed. The PES agreements in sub-watershed Cikapundung are occurred between Pustanling with Giri Putri farmer community in Cikole Village and PT AETRA with Syurga Air farmer community in Suntenjaya Village. BPLHD's role in this mechanism is as the mediator. The mechanism in sub-watershed Cikapundung is not a sustainable mechanism. The sustainable PES mechanism should meet these criterions: realistic, voluntarily, conditional, dan pro-poor 
(Munawir, 2009). The PES mechanism in sub-watershed Cikapundung does not completely fulfills those criteria.

This research aims to formulate the strategy to achieve the sustainable PES mechanism in Cikapundung sub-watershed. Qualitative method is applied in this research. Data collection is conducted by interviewing and distributing the questionnaire to the Syurga Air and Giri Putri farmer communities, PT AETRA, Pustanling, BPLHD and LP3ES. This research is using gap analysis, the role of factor analysis, and SWOT analysis. The institution problem in managing and monitoring the PES program in the field is also considered as the trigger of the unsustainable PES mechanism in Cikapundung subwater shed. Moreover, the insufficient budget for the program is also an obstacle for the land conservation. In order to achieve the sustainable PES mechanism, it is needed to form a mediator not from the government staff to facilitate, advocate, and coordinate PES mechanism to make it more effective, also increasing the law compliance, optimize the working group, enhancing the stakeholder's performance, and negotiating with the potential buyer.

Keywords: payment foe environmental services, Cikapundung sub-watershed, SWOT analysis

\section{PENDAHULUAN}

Pengelolaan DAS adalah

rangkaian upaya perumusan tujuan, sinkronisasi program, pelaksanaan dan pengendalian pengelolaan sumberdaya DAS lintas para pemangku kepentingan secara partisipatif berdasarkan kajian kondisi biofisik, ekonomi, sosial, politik dan kelembagaan guna mewujudkan tujuan pengelolaan DAS (Kodoatie dan Syarif 2010). Pada rangkaian manajemen DAS terdapat aktivitas pengelolaan yang melibatkan hubungan timbal balik antara SDA dengan masyarakat. Dalam pelaksanaannya terjadinya dampak hubungan timbal balik antara manusia dengan lingkungan yang secara spesifik dikenal dengan eksternalitas (Sankar, 2008). Terkait dengan eksternalitas tersebut, sebagai salah satu upaya untuk mengurangi kerusakan lingkungan dan meningkatkan kesejahteraan masyarakat, terutama di kawasan DAS dapat diterapkan konsep Imbal Jasa Lingkungan (IJL) atau populer dengan istilah Payment for Environmental Services (PES) (LP3ES, 2009).Pagiola (2005) dalam Economic and Social Commission for Asia and the Pasific (2009) mendefinisikan IJL sebagai transaksi sukarela untuk jasa lingkungan yang telah didefinisikan secara jelas, dibeli oleh pembeli jasa lingkungan dari sedikit-dikitnya seorang penyedia jasa lingkungan, jika penyedia jasa lingkungan tersebut memenuhi persyaratan dalam perjanjian dan menjamin penyediaan jasa lingkungan.

Sub-DAS Cikapundung masih sangat potensial bagi penyediaan air untuk kebutuhan penduduk. Akan tetapi, saat ini debit air bulanan di sungai ini sangat mengalami penurunan hingga 20 $30 \%$ dari debit normal (Maria, 2008).Erosi yang dihasilkan sub-DAS Cikapundung mencapai 450 ton per ha setiap tahun. Bagi PT Aetra Air Jakarta, wilayah hilir Cikapundung adalah salah satu sumber air baku perusahaannya (PT Aetra, 2009). Di kawasan Desa Cikole dan Desa Suntenjaya, yang masih termasuk dalam kawasan hulu dan daerah tangkapan air Sungai Cikapundung, dilakukan pengelolaan DAS dengan menerapkan konsep IJL (Munawir, 2009).

Terdapat dua kelompok petani pada mekanisme IJL ini, yaitu kelompok tani Giri Putri (Desa Cikole) dan kelompok Syurga Air (Desa Suntenjaya). Mereka berperan sebagai penyedia jasa lingkungan yang mendapatkan kompensasi atau pembayaran jasa lingkungan dari pihak pemanfaat air yang berada di daerah hilir. Pelaksanaan program IJL ini dimulai dari Juni 2009 hingga Desember 2012. Namun, dalam pelaksanaannya mekanisme IJL menemukan kesulitan dalam mewujudkan keberlanjutan program (BPLHD, 2010). Selain itu, Nawir (2008) menyebutkan bahwa tidak terdapat tindak lanjut pelatihan yang terfokus pada pemberdayaan masyarakat seutuhnya dan masih kurangnya pendampingan untuk pelaksanaan program jasa lingkungan. Penelitian ini bertujuan untuk mengetahui faktor-faktor yang mempengaruhi berjalannya mekanisme IJL di sub-DAS Cikapundung 
dan strategi agar mekanisme tersebut menjadi berkelanjutan.

Secara teoritis penelitian ini diharapkan dapat memberikan sumbangan pemikiran bagi pengembangan ilmu pengetahuan tentang peningkatan kualitas lingkungan melalui pengelolaan mekanisme Imbal Jasa Lingkungan. Secara praktis hasil penelitian ini diharapkan menjadi bahan masukan bagi Pemerintah Daerah Kabupaten Bandung Barat dalam pelaksanaan pengelolaan mekanisme Imbal Jasa Lingkungan terutama dalam hal pengambilan keputusan yang akan diambil selanjutnya dalam upaya peningkatan kualitas lingkungan hidup dan pemberdayaan masyarakat.

\section{METODE}

Metode penelitian yang digunakan adalah metode kualitatif dengan analisis deskriptif (Sarwono, 2011) yang bertujuan untuk menjelaskan berjalannya mekanisme IJL di sub-DAS Cikapundung saat ini dan faktor-faktor yang berpengaruh terhadap berjalannya mekanisme tersebut dan merumuskan strategi yang harus dilakukan agar mekanisme IJL di sub-DAS Cikapundung menjadi berkelanjutan.

Analisis data dilakukan dengan menggunakan analisis kesenjangan, analisis peran faktor dan analisis SWOT. Analisis kesenjangan merupakan salah satu metode yang umum digunakan dalam suatu pengelolaan manajemen (Supriatna, 2008). Kriteria mekanisme IJL dilihat dari hal berikut: realistic, voluntarily, conditional, dan propoor(Munawir, 2009). Sehingga, untuk mengetahui bagaimana berjalannya mekanisme IJL di sub-DAS Cikapundung, dilakukan analisis kesenjangan antara mekanisme IJL di sub-DAS Cikapundung dengan mekanisme IJL yang berkelanjutan berdasarkan empat kriteria tersebut. Hasil yang diperoleh dari pengukuran indikator-indikator pada setiap kriteria pada mekanisme IJL dan hasil analisis kesenjangan (Kerlinger,1990), kemudian digunakan untuk mengidentifikasi faktor-faktor yang berpengaruh terhadap berjalannya mekanisme IJL di sub-DAS Cikapundung.
Selanjutnya faktor-faktor tersebut dianalisis secara deskriptif untuk memaparkan peranan masing-masing faktor dalam mendorong atau menghambat berjalannya mekanisme IJL di sub_DAS Cikapundung.

Langkah selanjutnya yang dilaksanakan setelah tahapan pengumpulan data melalui wawancara adalah diskusi kelompok. Wawancara dilakukan dengan pihak PT Aetra, Pustanling Kementerian Kehutanan, Kelompoktani Sunten Jaya dan Giri Putri pada bulan April 2012. Informan kunci masing-masing adalah satu orang mewakili kelompok mereka.

Kemudian, diskusi dilakukan untuk mendukung analisis SWOT, yaitu untuk mendiskusikan faktor-faktor yang berpengaruh pada mekanisme IJL di subDAS Cikapundung. Diskusi dilakukan dengan pihak-pihak yang diwawancara beserta20 total anggota dari seluluh kelompok. Diskusi dilakukan pada April 2012 di BPLHD Bandung. Dari data yang telah dikumpulkan, kemudian diklasifikasikan yang termasuk dalam faktor eksternal dan internal. Lalu diberikan bobot pada setiap faktor yang ada. Dengan hasil pembobotan selanjutnya dapat disimpulkan strategi yang dapat dilakukan sesuai dengan perpaduan strategi dalam matrik SWOT (Rangkuti, 1998).

\section{HASIL PEMBAHASAN}

\section{Mekanisme IJL di sub-DAS Cikapundung}

Pada mekanisme IJL di Desa Cikole, dana yang diberikan kepada kelompok tani Giri Putri berasal dari APBD. Para petani pada kelompok tani Giri Putri kemudian bertanggung jawab untuk mengelola dana yang diberikan sesuai dengan maksud dan tujuan pemberian dana. Kegiatan yang dilakukan dengan dana kompensasi disajikan pada Tabel 1. 
Tabel 1.Transaksi IJL di Desa Cikole

\begin{tabular}{|c|l|l|}
\hline $\begin{array}{c}\text { Tahapan } \\
\text { Transaksi }\end{array}$ & $\begin{array}{c}\text { Jumlah Dana } \\
\text { yang Diberikan }\end{array}$ & Kegiatan \\
\hline Transaksi 1 & Rp. 7.500.000 & Training \\
\hline Transaksi 2 & Rp. 10.836.000 & $\begin{array}{l}\text { Pembuatan } \\
\text { persemaian }\end{array}$ \\
\hline Transaksi 3 & Rp. 20.168.500 & $\begin{array}{l}\text { Pembelian } \\
\text { bibit }\end{array}$ \\
& & Pengarahan \\
& Rp. 2.000.000 & \\
\hline Transaksi 4 & & \\
& & \\
\hline Total dana & Rp. 40.504 .500 & \\
\hline
\end{tabular}

Sumber: hasil wawancara

Sesuai dengan kesepakatan antara PT Aetra dan kelompok tani Syurga Air di Desa Suntenjaya, kelompok tani Syurga Air melaksanakan upaya konservasi air serta lahan melalui penanaman. perawatan, juga menjaga tanaman dan melaksanakan rangkaian kegiatan lainnya yang terkait dengan upaya pelestarian fungsi DAS. Naskah kesepakatan tersebut terdapat pada perjanjian PT Aetra Air Jakarta dengan Kelompok Tani Syurga Air Desa Sunten Jaya Nomor: 063/AGRSA/ IX/09 tentang Membangun Mekanisme Hubungan Hulu-Hilir Dalam Upaya Pelestarian Sumberdaya Air Di DAS Citarum. Pada tahap pertama PT Aetra membayar 50\% dari total kompensasi sebesar Rp. 50.000.000. Setelah itu di tahapan kedua, 25\% diberikan setelah 3 bulan dari pembayaran pertama. Sisa pembayaran dilakukan di tahapan ketiga setelah 6 bulan kemudian.

Berdasarkan hasil wawancara dengan BPLHD, pada saat dilakukan pemantauan ke wilayah Desa Suntenjaya, kegiatan yang mencakup program IJL antara PT Aetra dan kelompok tani Syurga Air Desa Sunten Jaya adalah sebagai berikut:
- Kelompok tani Giri Putri memiliki kewajiban untuk melakukan penghijauan sebagai wujud pelestarian sumberdaya air di sub-DAS Cikapundung.

- Training pembuatan pestisida alami untuk petanipetani.

- Kelompok tani Giri Putri melakukan penanaman pohon pada lahan yang dimiliki petani dengan total luas 33 ha.

- Pembelian bibit serta bahan-bahan lainnya yang dibutuhkan pada proses penanaman.

- Pustanling mengharapkan hasil yang maksimal dari penanaman yang dilakukan kelompok tani. 10.000 tanaman kopi ditanam berselang dengan tanaman sayuran seperti brokoli, sedangkan tanaman suren dan eucalyptus ditanam di pinggir-pinggir tanaman sayuran.

- YPC menyelenggarakan pengarahan yang ditujukan untuk kelompok tani. Kegiatan ini dilakukan sekali sebulan.

- Melalui kegiatan ini, para petani dan pendamping kelompok tani saling bertukar pendapat dan mencari solusi terbaik untuk setiap permasalahan yang dihadapi di lapangan.

1. Penanaman dilaksanakan pada lahan milik masyarakat di sekitar Desa Suntenjaya dengan pola penanaman kebun campuran (jangka pendek ditanami sayuran, jangka menengah ditanami kopi dan jangka panjang ditanami suren)

2. Bantuan yang didistribusikan oleh PT Aetra Air Jakarta sejumlah 23.000 pohon yang terdiri dari, 3.000 pohon suren dan 20.000 pohon kopi.

3. Di samping itu, petani Syurga Air mempunyai persemaian tanaman kopi sejumlah 16.000 pohon, dan membutuhkan mesin pencacahkopi untuk pengelolaan pasca panen kopi.

4. Peternakan sapi yang berada di Kecamatan Lembang cukup banyak, kurang lebih terdapat 28.000 ekor. Permasalahan lain yang dijumpai di Desa Suntenjaya adalah kotoran sapi yang menjadi sumber pencemaran dan belum ada pengelolaan secara baik.

\section{Faktor-faktor yang Mempengaruhi Mekanisme IJL sub-DAS Cikapundung}

Berdasarkan hasil analisis kesenjangan yang ditinjau dari kriteria realistic, voluntarily, conditional, dan pro-poor(Munawir, 2009) maka 
terlihat bahwa belum seluruhnya kriteria IJL di sub-DAS Cikapundung dapat terpenuhi, seperti yang tersaji pada Tabel 2. berikut ini.

Tabel 2. Kesenjangan mekanisme IJL berkelanjutan dan mekanisme IJL di sub-DAS Cikapundung

\begin{tabular}{|c|c|c|c|c|}
\hline \multirow[t]{2}{*}{ Kriteria } & \multirow[t]{2}{*}{ Indikator } & \multirow{2}{*}{$\begin{array}{l}\text { Mekaniseme IJL } \\
\text { Berkelanjutan } \\
\text { di DASCidanau }\end{array}$} & \multicolumn{2}{|c|}{ Mekanisme IJL di sub-DASGikapundung } \\
\hline & & & Aspek & $\begin{array}{l}\text { Kriteria Sudah/ } \\
\text { Belum Dipenuhi }\end{array}$ \\
\hline \multirow[t]{5}{*}{ Realistic } & $\begin{array}{l}\text { 1. Upaya agar } \\
\text { program dapat } \\
\text { dilakukan. }\end{array}$ & $\begin{array}{l}\text { - Koordinasi yang efektif. } \\
\text { - Petani diarahkan untuk } \\
\text { berkomitmen penuh } \\
\text { pada program } \\
\text { - Konservasi tanah sesuai } \\
\text { dengan luas lahan kritis. }\end{array}$ & $\begin{array}{l}\text { - Overlapping } \\
\text { koordinasi } \\
\text { - Fokus petani } \\
\text { belum } 100 \% \\
\text { pada program IJL. } \\
\text { - Konservasiah } \\
\text { belum sesuai } \\
\text { dengan luas lahan } \\
\text { kritis. } \\
\end{array}$ & - Belum dipenuhi \\
\hline & $\begin{array}{l}\text { 2. Memiliki } \\
\text { kemampuan untuk } \\
\text { mencapai tujuan. }\end{array}$ & $\begin{array}{l}\text { - Mendorong } \\
\text { pengembangan } \\
\text { mekanisme IJL untuk } \\
\text { manajemen DAS dan } \\
\text { peningkatan mata } \\
\text { pencaharian. }\end{array}$ & $\begin{array}{l}\text { - Tujuan program } \\
\text { belum } \\
\text { sepenuhnya } \\
\text { tercapai } \\
\text { sementara } \\
\text { kontrak belum } \\
\text { diperpanjang } \\
\text { oleh pemanfaat } \\
\text { jasa lingkungan. }\end{array}$ & - Belum dipenuhi \\
\hline & $\begin{array}{l}\text { 3.Jasa IJL yang terikat } \\
\text { perjanjian. }\end{array}$ & $\begin{array}{l}\text { - Rangkaian kegiatan } \\
\text { konservasi diatur dalam } \\
\text { kontrak kesepakatan. }\end{array}$ & $\begin{array}{l}\text { - Rangkaian } \\
\text { kegiatan } \\
\text { konservasi } \\
\text { diatur dalam } \\
\text { kontrak } \\
\text { kesepakatan. } \\
\end{array}$ & - Sudah dipenuhi \\
\hline & $\begin{array}{l}\text { 4.Jenis pasar jasa } \\
\text { lingkungan }\end{array}$ & $\begin{array}{l}\text { - Penyedia jasa lingkungan } \\
\text { masih terikat kontrak } \\
\text { sejak } 2005 \text {. }\end{array}$ & $\begin{array}{l}\text { - } \text { Kontrak IJL } \\
\text { belum } \\
\text { diperpanjang. } \\
\end{array}$ & - Belum dipenuhi \\
\hline & $\begin{array}{l}\text { 5.Transaksi yang } \\
\text { terorganisir secara } \\
\text { mandiri. }\end{array}$ & $\begin{array}{l}\text { - Terdapat lembaga } \\
\text { pengelola dana yang } \\
\text { transparan yang } \\
\text { sekaligus berperan } \\
\text { sebagai mediator dalam } \\
\text { mekanisme. } \\
\text { - Dana yang diberikan } \\
\text { dapat dikelola dengan } \\
\text { efisien. }\end{array}$ & $\begin{array}{l}\text { - Mediator adalah } \\
\text { bagian dari } \\
\text { pemerintahan } \\
\text { (BPLHD). } \\
\text { - Dana yang } \\
\text { diberikan belum } \\
\text { mencukupi } \\
\text { untuk kegiatan } \\
\text { program. } \\
\end{array}$ & - Belum dipenuhi \\
\hline Voluntarily & $\begin{array}{l}\text { 6.Pelaksanaan } \\
\text { program IJL tanpa } \\
\text { adanya tekanan } \\
\text { pihak lain. }\end{array}$ & $\begin{array}{l}\text { - Motivasi untuk } \\
\text { melakukan konservasi } \\
\text { lahan dating dari pihak } \\
\text { pemanfaat jasa } \\
\text { lingkungan. }\end{array}$ & $\begin{array}{l}\text { - Motivasi untuk } \\
\text { melakukan } \\
\text { konservasi lahan } \\
\text { dating dari pihak } \\
\text { pemanfaat jasa } \\
\text { lingkungan. }\end{array}$ & - Sudah dipenuhi \\
\hline Conditional & $\begin{array}{l}\text { 7.Hal-hal yang harus } \\
\text { dipenuhi seperti } \\
\text { yang tercantum } \\
\text { dalam kesepakatan. }\end{array}$ & $\begin{array}{l}\text { - Benefit yang disesuaikan } \\
\text { dengan performa yang } \\
\text { disetujui melalui } \\
\text { kontrak. } \\
\text { • Jasa lingkungan sudah } \\
\text { termasuk dengan semua } \\
\text { kegiatan, alokasi, dan } \\
\text { jenis pembayaran, serta } \\
\text { skema distribusi di } \\
\text { tingkat masyarakat. }\end{array}$ & $\begin{array}{l}\text { - Jasa lingkungan } \\
\text { sudah termasuk } \\
\text { dengan semua } \\
\text { kegiatan, alokasi, } \\
\text { dan jenis } \\
\text { pembayaran, } \\
\text { serta skema } \\
\text { distribusi di } \\
\text { tingkat } \\
\text { masyarakat } \\
\end{array}$ & - Sudah dipenuhi \\
\hline Pro-poor & $\begin{array}{l}\text { 8.Peningkatan } \\
\text { kesejahteraan } \\
\text { kelompok tani. }\end{array}$ & $\begin{array}{l}\text { - Peningkatan modal } \\
\text { penghidupan } \\
\text { berkelanjutan dari sisi } \\
\text { finansial, sosial dan SDM. }\end{array}$ & $\begin{array}{l}\text { - Peningkatan } \\
\text { hasil panen } \\
\text { kelompok tani. }\end{array}$ & - Sudah dipenuhi \\
\hline
\end{tabular}


Apabila diasumsikan bahwa kedelapan indikator pada keempat kriteria IJL memiliki bobot yang sama dalam mempengaruhi terwujudnya mekanisme IJL yang berkelanjutan, maka mekanisme IJL di sub-DAS Cikapundung hanya dipenuhi sebesar 50\%. Berdasarkan persentase tersebut maka mekanisme IJL di sub-DAS Cikapundung belum sepenuhnya berada pada kondisi mekanisme IJL yang berkelanjutan. Persentase tersebut berada pada posisi pertengahan, atau bisa dikatakan bahwa kegagalan pada program ini sebanding dengan keberhasilannya. Pada pelaksanaan program IJL yang berkelanjutan, ke semua kriteria harus terpenuhi dengan baik. Sehingga dapat dikatakan bahwa semua pihak yang terlibat dalam mekanisme IJL di sub-DAS Cikapundung perlu memperbaiki pelaksanaan program IJL agar ke depannya IJL dapat benar-benar memberikan manfaat untuk semua pihak dan meningkatkan kualitas air di kawasan tersebut serta mampu mewujudkan pengelolaan kawasan sub-DAS yang memadai.

Melalui analisis kesenjangan tersebut dapat pula dilakukan suatu analisa peran faktor yang menghambat terwujudnya mekanisme IJL yang berkelanjutan, yaitu:

1. Program IJL yang dilakukan oleh PT Aetra dan Pustanling hanya fokus terhadap permasalahan yang timbul akibat pengelolaan lahan terhadap kualitas air, sehingga pencemaran yang disebabkan kotoran ternak sapi masih kurang menjadi perhatian.

2. Kedua kelompok tani (Syurga Air dan Giri Putri) telah mendapatkan bekal berupa pelatihan untuk pengkomposan, namun kendala keterbatasan biaya dalam implementasinya masih saja dihadapi.

Kegagalan juga terjadi karena terkadang petani yang tergabung dalam kelompok tani cenderung sulit membagi waktu untuk memfokuskan diri merawat tanaman sebagaimana mestinya. Para petani tersebut memiliki lahan lain yang harus dikelola dan juga harus mengurus ternak sapi. Kegiatan-kegiatan tersebut cukup menyita waktu sehingga perawatan terhadap tanaman bukan menjadi prioritas. Selain itu, pada saat kelompok tani melakukan pelaporan terhadap Pustanling, tidak pernah ada tanggapan terhadap progress yang terjadi di lapangan. Semuanya hanya bergantung pada BPLHD dan pihak pendamping lainnya.

Langkah berikutnya adalah dengan melakukan analisis untuk merumuskan upaya-upaya yang sebaiknya dilakukan untuk mewujudkan mekanisme IJL yang berkelanjutan. Sehingga dilakukan analisa SWOT. Pada Tabel 3. dan 4. berikut ini terlihat hasil penilaian pada setiap unsur internal dan eksternal.

Tabel 3. Analisis faktor strategi internal pada mekanisme IJL sub-DAS Cikapundung

\begin{tabular}{|c|l|l|l|}
\hline Faktor Internal & Bobot & Rating & $\begin{array}{c}\text { Bobot } \\
\text { X } \\
\text { Rating }\end{array}$ \\
\hline strengths & & \\
\hline $\begin{array}{l}\text { 1.Penerapan kriteria IJL: } \\
\text { realistic, voluntarily, } \\
\text { conditional, pro-poor }\end{array}$ & 0,25 & 3 & 0,75 \\
\hline $\begin{array}{l}\text { 2. Kesepakatan antara PT } \\
\text { Aetra dan Desa Sunten } \\
\text { Jaya serta antara } \\
\text { Pustanling Kemenhut } \\
\text { dengan Desa Cikole }\end{array}$ & 0,20 & 4 & 0,80 \\
\hline $\begin{array}{l}\text { Total strength pemerintah } \\
\text { weakness konservasi }\end{array}$ & 0,15 & 3 & 0,45 \\
\hline $\begin{array}{l}\text { 1.Perhatian } \\
\text { terhadap } \\
\text { lahan belum optimal }\end{array}$ & & & \\
\hline $\begin{array}{l}\text { 2. Keterbatasan dana yang } \\
\text { tersedia untuk program } \\
\text { IJL }\end{array}$ & 0,15 & 4 & 0,60 \\
\hline $\begin{array}{l}\text { 3. Kurang optimalnya } \\
\text { kinerja stakeholders } \\
\text { pada program IJL }\end{array}$ & 0,10 & 3 & 0,30 \\
\hline $\begin{array}{l}\text { 4. Unsur eksternalitas } \\
\text { lingkungan yang kurang } \\
\text { memperhatikan } \\
\text { dampak terhadap pihak } \\
\text { lain }\end{array}$ & 0,15 & 3 & 0,45 \\
\hline Total weakness & 1,00 & & 3,35 \\
\hline Total faktor internal & & \\
\hline
\end{tabular}

Sumber: hasil pengolahan data (2013) 
Tabel 4. Analisis faktor strategi eksternal pada mekanisme IJL sub-DASCikapundung

\begin{tabular}{|c|c|c|c|}
\hline Faktor Eksternal & Bobot & Rating & Bobot x rating \\
\hline \multicolumn{4}{|l|}{ opportunities } \\
\hline $\begin{array}{l}\text { 1. Adanya pihak lain yang turut } \\
\text { mendukung program IJL, } \\
\text { seperti LSM dan SKPD }\end{array}$ & 0,25 & 4 & 1,00 \\
\hline 2. Fungsi sub-DASCikapundung & 0,15 & 4 & 0,60 \\
\hline $\begin{array}{l}\text { 3. UU No 40/2007 Perseroan } \\
\text { Terbatas (PT), pasal } 74 \text { tentang } \\
\text { Tanggung Jawab Sosial dan } \\
\text { Lingkungan Perusahaan } \\
\end{array}$ & 0,15 & 3 & 0,45 \\
\hline Total opportunity & & & 2,05 \\
\hline \multicolumn{4}{|l|}{ threats } \\
\hline $\begin{array}{l}\text { 1. Sulitnya menghindari setiap } \\
\text { jenis kerusakan yang terjadi di } \\
\text { sub-DAS Cikapundung }\end{array}$ & 0,25 & 4 & 1,00 \\
\hline $\begin{array}{l}\text { 2. Persepsi bahwa tanggung } \\
\text { jawab terbesar untuk } \\
\text { pemeliharaan kawasan sub- } \\
\text { DAS Cikapundung ada pada } \\
\text { pemerintah }\end{array}$ & 0,20 & 2 & 0,40 \\
\hline Total threat & & & 1,40 \\
\hline Total faktor eksternal & 1,00 & & 3.45 \\
\hline
\end{tabular}

Sumber: hasil pengolahan data (2013)

Berdasarkan hasil analisis faktor strategi eksternal dan internal pada mekanisme IJL di sub-DAS Cikapundung tersebut, maka dapat dilakukan identifikasi strategi untuk mewujudkan suatu mekanisme IJL yang berkelanjutan. Identifikasi dapat dilakukan dengan membuat matrik SWOT. Strategi diperoleh melalui wawancara dan diskusi kelompok dengan para stakeholders yang terlibat dalam mekanisme IJL di sub-DAS Cikapundung. Selain itu, studi literatur juga dijadikan acuan untuk menentukan strategi.

Strategi yang dipilih adalah strategi yang mampu membantu mewujudkan suatu mekanisme IJL yang berkelanjutan di sub-DAS Cikapundung.
Posisi strategis diperoleh dari hasil analisis strategis eksternal dan internal. Sesuai dengan hasil tersebut maka diketahui bahwa mekanisme IJL disubDAS Cikapundung berada pada kuadran ke I seperti yang dapat dilihat pada Gambar 1. Sehingga, strategi yang dapat dijalankan untuk mewujudkan mekanisme IJL yang berkelanjutan di subDAS Cikapundung adalah strategi yang berada di kuadran I. Strategi tersebut mengandalkan faktor strength dan opportunity. 
Tabel 5. Matrik SWOT mekanisme IJL di sub-DASCikapundung

\begin{tabular}{|c|c|c|}
\hline Faktor & $\begin{array}{l}\text { Strength: } \\
\text { - Penerapan kriteria IJL: } \\
\text { realistic, voluntarily, } \\
\text { conditional, pro-poor } \\
\text { - Kesepakatan antara PT } \\
\text { Aetra dan Desa Sunten } \\
\text { Jaya serta antara } \\
\text { Pustanling Kemenhut } \\
\text { dengan Desa Cikole }\end{array}$ & $\begin{array}{l}\text { Weakness: } \\
\text { - Perhatian pemerintah } \\
\text { terhadap konservasi } \\
\text { lahan belum optimal } \\
\text { - Keterbatasan dana yang } \\
\text { tersedia untuk program } \\
\text { IJL } \\
\text { - Kurang optimalnya } \\
\text { kinerja stakeholders } \\
\text { pada program IJL } \\
\text { - Unsur eksternalitas } \\
\text { lingkungan yang kurang } \\
\text { memperhatikan dampak } \\
\text { terhadap pihak lain }\end{array}$ \\
\hline \multicolumn{3}{|l|}{ Faktor eksternal } \\
\hline $\begin{array}{l}\text { Opportunity: } \\
\text { - Adanya pihak lain yang turut } \\
\text { mendukung program IJL, } \\
\text { seperti LSM dan SKPD } \\
\text { - Fungsi sub-DAS Cikapundung } \\
\text { - UU No 40/2007 Perseroan } \\
\text { Terbatas (PT), pasal } 74 \\
\text { tentang Tanggung Jawab } \\
\text { Sosial dan Lingkungan } \\
\text { Perusahaan }\end{array}$ & \begin{tabular}{llr} 
& \multicolumn{2}{c}{ S-O: } \\
- & Kepatuhan & pada \\
& regulasi & \\
- & Optimalisasi & forum \\
& pertemuan & \\
- & Meningkatkan & kinerja \\
& stakeholders & \\
- & Negosiasi & dengan \\
& potential buyer & \\
- & Pembentukan & lembaga \\
& mediator & yang \\
& independen &
\end{tabular} & $\begin{array}{l}\text { W-O: } \\
\text { - } \text { Penambahan dana } \\
\text { untuk program IJL } \\
\text { sesuai kebutuhan } \\
\text { program. } \\
\text { - } \text { Meningkatkan kinerja } \\
\text { pendampingan untuk } \\
\text { membantu kelompok } \\
\text { tani. } \\
\text { - Menghindari overlap } \\
\text { tugas pendampingan } \\
\text { kelompok tani dengan } \\
\text { membagi tanggung } \\
\text { jawab pendampingan. }\end{array}$ \\
\hline $\begin{array}{l}\text { Threat: } \\
\text { - Sulitnya menghindari setiap } \\
\text { jenis kerusakan yang terjadi } \\
\text { di sub-DAS Cikapundung } \\
\text { - Persepsi bahwa tanggung } \\
\text { jawab terbesar untuk } \\
\text { pemeliharaan kawasan sub- } \\
\text { DAS Cikapundung ada pada } \\
\text { pemerintah }\end{array}$ & \begin{tabular}{lr}
\multicolumn{3}{c}{ S-T: } \\
- Membangun kerjasama \\
yang solid antara para \\
pihak yang terkait \\
dengan program IJL di \\
- sub-DAS Cikapundung. \\
- Mengembangkan \\
pemahaman r para \\
pemanfaat r jasa \\
lingkungan & akan \\
keuntungan & dan \\
pentingnya & melakukan \\
konservasi & agar \\
memacu & mereka \\
memberikan & \\
kompensasi & bagi \\
kelompok tani. &
\end{tabular} & $\begin{array}{l}\text { - W-T: } \\
\text { - Meningkatkan kualitas } \\
\text { pelatihan mengenai } \\
\text { konservasi lahan dan } \\
\text { pengelolaan DAS. } \\
\text { - Memanfaatkan dana } \\
\text { yang diserahkan sebaik- } \\
\text { baiknya untuk hasil } \\
\text { maksimal dari program } \\
\text { IJL. } \\
\text { Meningkatkan } \\
\text { kerjasama dan } \\
\text { komitmen antar pihak } \\
\text { yang terlibat. }\end{array}$ \\
\hline
\end{tabular}

Sumber: hasil diskusi kelompok dan wawancara 


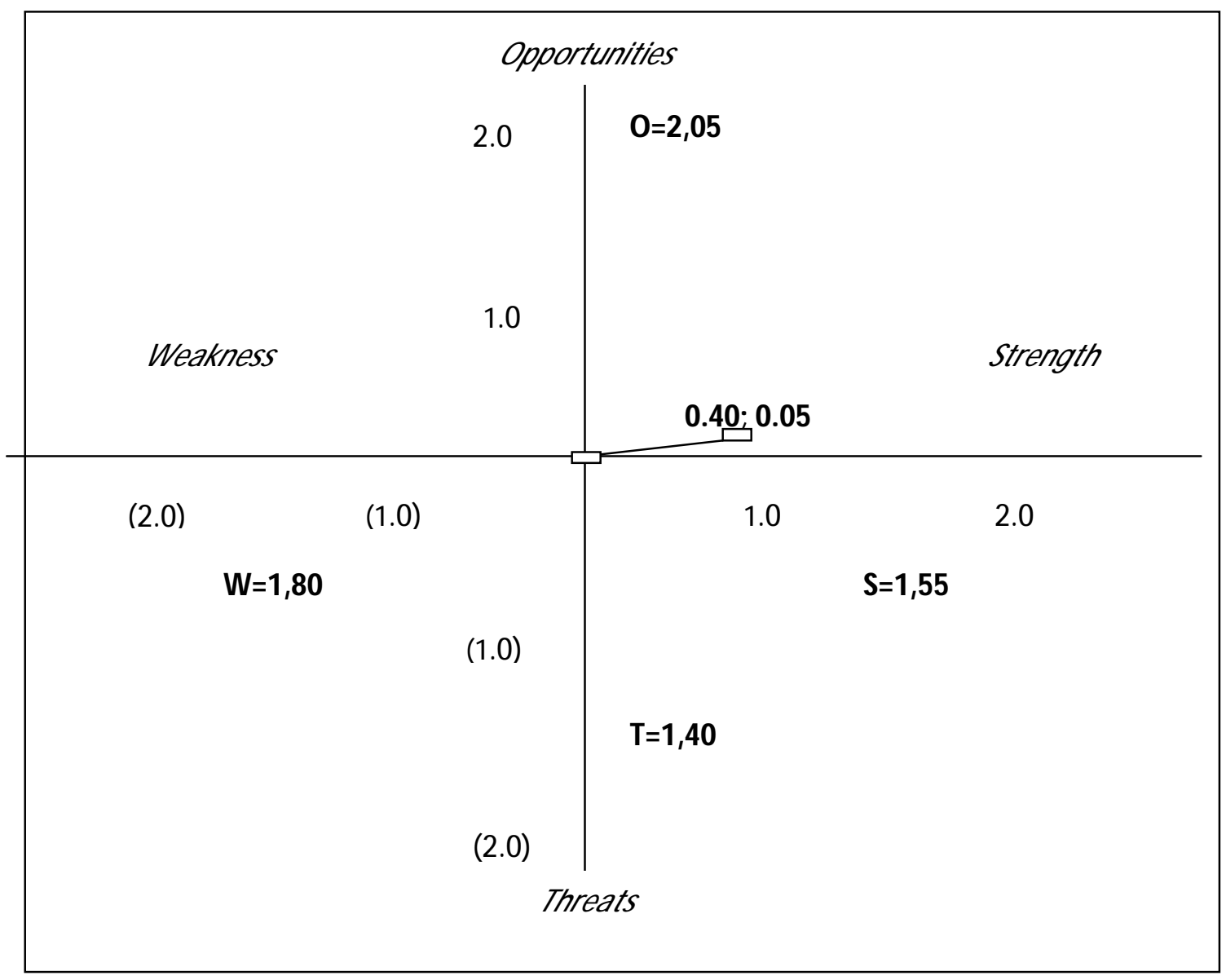

Gambar 1: Posisi strategis mekanisme IJL di sub-DAS Cikapundung

(Sumber: pengolahan data 2013)

Sesuai dengan hasil analisis SWOT yang dilakukan seperti yang ditunjukkan pada matrik SWOT mekanisme IJL di subDAS Cikapundung, maka strategi yang dapat dilakukan untuk mewujudkan meknaisme IJL yang berkelanjutan merupakan perpaduan antara faktor strength dan opportunity yang terdapat pada mekanisme IJL di sub-DAS Cikapundung yaitu melakukan upaya untuk meningkatkan kepatuhan pada regulasi terkait IJL, meningkatkan optimalisasi setiap forum pertemuan, meningkatkan kinerja stakeholders, melakukan negosiasi dengan potential buyer, dan membentuk lembaga mediator mekanisme IJL yang bukan dari institusi pemerintah agar fasilitasi, advokasi dan koordinasi mekanisme IJL lebih optimal.

\section{SI MPULAN}

1. Mekanisme Imbal Jasa Lingkungan (IJL) di sub-DAS Cikapundung dilakukan antara PT Aetra dengan Kelompok Tani Syurga Air dan Pustanling dengan Kelompok Tani Giri Putri. Dalam hal ini PT Aetra dan Pustanling menetapkan besaran kompensasi dan memberikannya kepada kelompok tani melalui BPLHD. Pelaksanaan IJL ini belum sepenuhnya memenuhi kriteria-kriteria yang ada pada suatu mekanisme IJL yang berkelanjutan, yaitu: realistic, voluntarily, conditional, dan pro-poor. Kriteria-kriteria yang belum seluruhnya terpenuhi tersebut menyebabkan mekanisme IJL di subDAS Cikapundung belum termasuk suatu mekanisme IJL yang berkelanjutan. Terdapat faktor-faktor internal dan eksternal yang mendukung maupun menghambat terciptanya mekanisme IJL yang berkelanjutan di sub-DAS Cikapundung, yaitu: 
a. Faktor internal yang mendukung: terdapat penerapan criteria IJL (realistic, voluntarily, conditional, propoor) dan adanya kesepakatan antara PT Aetra dan Desa Sunten Jaya serta antara Pustanling Kemenhut dengan Desa Cikole. Sedangkan faktor internal yang menghambat yaitu: perhatian pemerintah terhadap konservasi lahan belum optimal, keterbatasan dana yang tersedia untuk program IJL, kurang optimalnya kinerja stakeholders pada program IJL, dan unsur eksternalitas lingkungan yang kurang memperhatikan dampak terhadap pihak lain.

b. Faktor eksternal yang mendukung: adanya pihak lain yang turut mendukung program IJL, seperti LSM dan SKPD, fungsi sub-DAS Cikapundung, UU No 40/2007 Perseroan Terbatas (PT), pasal 74 tentang Tanggung Jawab Sosial dan Lingkungan Perusahaan. Sedangkan faktor eksternal yang menghambat yaitu: sulitnya menghindari setiap jenis kerusakan yang terjadi di subDAS Cikapundung dan munculnya persepsi bahwa tanggung jawab terbesar untuk pemeliharaan kawasan sub-DAS Cikapundung ada pada pemerintah.

2. Untuk mewujudkan suatu mekanisme IJL yang berkelanjutan di sub-DAS Cikapundung maka dapat dilakukan upaya untuk meningkatkan kepatuhan pada regulasi terkait IJL, meningkatkan optimalisasi setiap forum pertemuan, meningkatkan kinerja stakeholders, melakukan negosiasi dengan potential buyer, dan membentuk lembaga mediator mekanisme IJL yang bukan dari institusi pemerintah agar fasilitasi, advokasi dan koordinasi mekanisme IJL lebih optimal.

\section{SARAN}

Dalam upaya mendukung pelaksanaan strategi-strategi tersebut, maka disarankan untuk melakukan kajian berikut ini:

a. Secara praktis:

1) Mempertimbangkan jenis tanaman yang digunakan dalam upaya konservasi agar benar-benar memberi dampak positif terhadap kualitas dan kuantitas air.

2) Penetapan jumlah dana yang akan diberikan kepada kelompok tani agar disesuaikan dengan kebutuhan di lapangan untuk maksimalisasi hasil konservasi lahan.

b. Secara teoritis:

1) Kajian untuk melengkapi IJL dengan indikator yang jelas akan keberhasilan dampak dari kegiatan rehabilitasi terhadap sedimentasi dan erosi, sehingga menarik bagi pembeli jasa lingkungan dan dapat dilakukan perluasan ke wilayah lain. Saran ini dapat pula dijadikan masukan secara teoritis untuk penelitian mengenai program IJL selanjutnya.

\section{UCAPAN TERIMA KASIH}

Diucapkan terima kasih kepada

Depdiknas atas kesempatan dan dukungan finansial dalam bentuk beasiswa "Double Degree" Program Studi Magister Ilmu Lingkungan Konsentrasi Manajemen Sumber Daya Alam Universitas Padjajaran.

\section{DAFTAR PUSTAKA}

BPLHD. 2010. Laporan Mekanisme Imbal Jasa Lingkungan Di Desa Cikole dan Desa Sunten Jaya. Bandung.BPLHD.

Economic and Sosial Commission for Asia and the Pasific. 2009. Kebijakan Sosial Ekonomi Inovatif untuk Meningkatkan Kinerja Lingkungan; Imbal Jasa Lingkungan. Thailand: United Nations.

Kerlinger, F. N. 1990. Asas-asas Penelitian Behavioral. Edisi 3. Yogyakarta: Gajah Mada University Press.

Kodoatie, J. dan R.Sjarief, 2010. Tata Ruang Air. Yogyakarta: Penerbit Andi.

LP3ES. 2009. Program Pembayaran Jasa Perlindungan DAS; Mengembangkan Mekanisme Transaksi Hulu-Hilir untuk Meningkatkan Kehidupan 
Masyarakat. Jakarta: PSDALLP3ES \& IIED.

Maria, R. 2008. Hidrogeologi dan Potensi Resapan Air Tanah Sub Das Cikapundung Bagian Tengah. Jurnal Riset Geologi dan Pertambangan Jilid 18 No. 2. Bandung: Pusat Penelitian Geoteknologi Lembaga Ilmu Pengetahuan Indonesia.

Munawir. 2009. Imbal Jasa Lingkungan DAS Cikapundung. Disampaikan pada Working Group Imbal Jasa Lingkungan DAS Cikapundung. Bandung.Jakarta: LP3ES.

Nawir, A. dan Rumboko, M. 2008. Rehabilitasi Hutan di Indonesia: Akan Kemanakah Arahnya Setelah Lebih dari Tiga Dasawarsa. Bogor: Center for International Forestry Research.

PT Aetra. 2009. Final Report Payment for Environmental Services. PT Aetra Air Jakarta.
Rangkuti, F. 1998. Analisis SWOT Teknik Membedah Kasus Bisnis: Reorientasi Konsep Perencanaan Strategis untuk MenghadapiAbad 21. Jakarta: PT. Gramedia Pustaka Utama.

Sankar, U. 2008. Environmental Externalities.Madras School of Economics. Chennai: Gandhi Mandapam Road.

Sarwono, J. 2011. Mixed Methods. Jakarta: PT Gramedia Pustaka Utama.

Supriatna, J. 2008. Melestarikan Alam Indonesia. Jakarta: Yayasan Obor Indonesia. 